\title{
Comparative Study of Breakdown Voltage of Mineral, Synthetic and Natural Oils and Based Mineral Oil Mixtures under AC and DC Voltages
}

\author{
Abderrahmane Beroual ${ }^{1, *}$, Usama Khaled ${ }^{2,3}$, Phanuel Seraphine Mbolo Noah ${ }^{1}$ \\ and Henry Sitorus 4 \\ 1 Ecole Centrale de Lyon, University of Lyon, Ampere CNRS UMR 5005, 36 avenue Guy Collongue, \\ 69134 Ecully, France; phanuel.noah@hotmail.fr \\ 2 Electrical Engineering Department, College of Engineering, King Saud University, Riyadh 11421, \\ Saudi Arabia; ukhaled@ksu.edu.sa \\ 3 Electrical Engineering Department, Faculty of Energy Engineering, Aswan University, Aswan 81528, Egypt \\ 4 Electrical Engineering Department, Engineering Faculty, Universitas Lampung (Unila), Bandar Lampung, \\ Lampung 35141, Indonesia; hbhstr@gmail.com \\ * Correspondence: Abderrahmane.Beroual@ec-lyon.fr; Tel.: +33-47-2186-110
}

Academic Editor: Pierre Trambouze

Received: 27 February 2017; Accepted: 23 March 2017; Published: 10 April 2017

\begin{abstract}
This paper deals with a comparative study of AC and DC breakdown voltages of based mineral oil mixtures with natural and synthetic esters mainly used in high voltage power transformers. The goal was to analyze the performances of oil mixtures from the dielectric withstand point of view and to predict the behavior of transformers originally filled with mineral oil and re-filled with synthetic or natural ester oils when emptied for maintenance. The study concerns mixtures based on $20 \%, 50 \%$, and $80 \%$ of natural and synthetic ester oils. AC breakdown voltages were measured using a sphere-sphere electrode system according to IEC 60156 specifications; the same specification was adopted for DC measurements since there is no standard specifications for this voltage waveform. A statistical analysis of the mean values, standard deviations, and histograms of breakdown voltage data was carried out. The Normal and Weibull distribution functions were used to analyze the experimental data and the best function that the data followed was used to estimate the breakdown voltage with risk of $1 \%, 10 \%$, and $50 \%$ probability. It was shown that whatever the applied voltage waveforms, ester oils always have a significantly higher breakdown voltage than mineral oil. The addition of only $20 \%$ of natural or synthetic ester oil was sufficient to considerably increase the breakdown voltage of mineral oil. The dielectric strength of such a mixture is much higher than that of mineral oil alone and can reach that of ester oils. From the point of view of dielectric strength, the mixtures constitute an option for improving the performance of mineral oil. Thus, re-filling of transformers containing up to $20 \%$ mineral oil residues with ester oils, does not present any problem; it is even advantageous when considering only the breakdown voltage. Under $\mathrm{AC}$, the mixtures with natural ester always follow the behavior of vegetable oil alone. With the exception of the $20 \%$ mixture of natural ester in DC, the breakdown voltage values of all the tested mixtures were in accordance with the normal distribution, which made it possible to define the breakdown voltages for the risk levels of $1 \%, 10 \%$, and $50 \%$ of probability.
\end{abstract}

Keywords: insulating oils; vegetable oil; synthetic oil; mineral oil; oil mixtures; AC breakdown voltage; DC breakdown voltage; re-filling of power transformers; statistical analysis; normal distribution; Weibull distribution 


\section{Introduction}

Mineral oil (petroleum product) remains today, the most used dielectric liquid in power transformers because of its lower cost and good physicochemical properties. However, its impact on the environment and in particular on aquatic resources and soils (biodegradability of mineral oil below $30 \%$ ) is a problem and not the least one that must be taken into account in the manufacture of new units (transformers) or the maintenance of old ones and their re-filling. Re-filling is a process of removing insulating liquid in a transformer in operation and replacing it with new oil. In general the liquid replaced is mineral oil. Indeed, it is more economical to replace the insulating liquid than to replace the transformers with new ones. However, governmental and non-governmental organizations presently recommend the replacement of mineral oils with vegetable oils whenever possible. It is therefore necessary to find new oils based on natural products (vegetable oils) therefore biodegradable whose properties would be near or even better than those of mineral oils. The problem of re-filling with other oil than mineral oil is that between $10 \%$ and $20 \%$ of the old liquid remains in the transformer. So it is necessary to ensure compatibility between the replaced oil and replacement oil and check for non-deterioration of the dielectric and physicochemical properties of the replacement oil; the mixture which will be then in the transformer must have at least the same breakdown voltage.

Perrier et al [1,2] investigated mixtures consisting of $80 \%$ of mineral oil with $20 \%$ of two other kinds of insulating liquids, namely silicon and synthetic ester oils; the aim being the improvement of the performance of mineral oil. They analyzed and compared the main properties required for an insulating liquid for power transformers such as miscibility, viscosity, heat transfer, breakdown voltage (BDV), ageing stability, and electrostatic charging tendency (ECT). These authors demonstrated that a mixture of mineral oil with $20 \%$ synthetic ester oil was sufficient to improve the characteristics of mineral oil, particularly its dielectric strength, aging stability, water solubility, and all without changing its viscosity. In fact, the good solubility of water in ester oil reduces the influence of moisture on the breakdown voltage of mineral oil.

The purpose of this paper is: (1) to compare the breakdown voltages of two ester oils, one synthetic and the other natural, with the breakdown voltage of mineral oil; and (2) to analyze the breakdown voltages of different mixtures based on mineral oil and these two esters at different concentrations. The goal is to predict the dielectric performances of each oil mixture before their use for re-filling high voltage oil-filled equipment especially power transformers.

\section{Experiment}

\subsection{Oils and Oil Mixtures}

The tested oils are inhibited naphthenic mineral oil (naphtenic type provided by Nynas AB, Stockholm, Sweden), vegetable oil (Envirotemp ${ }^{\mathrm{TM}}$ FR3 ${ }^{\mathrm{TM}}$, Cooper Power Systems, Waukesha, WI, USA) and synthetic ester oil (MIDEL 7131, M\&I Materials Ltd Hibernia, Manchester, UK). Their main characteristics are given in Table 1.

Table 1. Properties of tested oils. The flash point is measured according to Pensky-Martens (PM) closed-cup method according to ASTM D93.

\begin{tabular}{cccc}
\hline Properties & \multicolumn{3}{c}{ Type of Oil } \\
\cline { 2 - 4 } & $\begin{array}{c}\text { Napthenic } \\
\text { Mineral Oil Nynas }\end{array}$ & $\begin{array}{c}\text { Synthetic Ester Oil } \\
\text { MIDEL 7131 }\end{array}$ & $\begin{array}{c}\text { Natural Ester Oil } \\
\text { Envirotemp }^{\text {TM }} \text { FR3 }^{\text {TM }}\end{array}$ \\
\hline Density $\left(20^{\circ} \mathrm{C}\right) \mathrm{g} / \mathrm{cm}^{3}$ & 0.89 & 0.97 & 0.92 \\
Viscosity $\left(40^{\circ} \mathrm{C}\right) \mathrm{mm}^{2} / \mathrm{s}$ & 8.9 & 28 & 36 \\
Acid index $(\mathrm{mg} \mathrm{KOH} / \mathrm{g})_{\text {Pour point }{ }^{\circ} \mathrm{C}}$ & $<0.01$ & 0.01 & 0.022 \\
Flash point ${ }^{\circ} \mathrm{C}(\mathrm{PM} \mathrm{method)}$ & -57 & -60 & -21 \\
Dissipation factor $\left(90^{\circ} \mathrm{C}\right)$ & 148 & 260 & 330 \\
Dielectric constant $\left(20^{\circ} \mathrm{C}\right)$ & $<0.001$ & $<0.006$ & 0.005 \\
Breakdown voltage $\mathrm{kV}$ & 2.2 & 3.2 & 3.2 \\
Relative water content at $20^{\circ} \mathrm{C}(\%)$ & $>70$ & $>75(\mathrm{IEC}$ 60156) & $56($ ASTM 1816) \\
\hline
\end{tabular}


The liquids are mixed at ambient temperature with the aid of a magnetic stirrer at a speed of $1100 \mathrm{rpm}$ for about $30 \mathrm{~min}$. To ensure the miscibility of mineral oil with both ester types, mixtures were prepared and left for several days at rest. After that, a homogeneous mixture (without emulsion) was observed visually. Then the miscibility was checked similarly as in previous work $[1,2]$. All the mixtures were homogeneous before and after ageing and no abnormal evolution of acidity occurred. Small glass bottles $(500 \mathrm{~mL})$ were used to reduce the empty space between the oil surface and the bottle lid and thus reduce the absorption of moisture by oil.

Before each test, the water content of each sample was measured (Table 2) according to IEC 60814 [3] and using a Mettler-Toledo Karl Fischer DL32 coulometer (Mettler-Toledo GmbH, Analytical, Schwerzenbach, Switzerland) [4].

Table 2. Water contents of oils and oil mixtures before testing at ambient: $\left(^{*}\right)$ in AC and $\left(^{* *}\right)$ in DC.

\begin{tabular}{cc}
\hline Oil/Oil Mixtures & Water Content (ppm) \\
\hline Mineral oil NYNAS (MO) & $17.94^{*}$ \\
\hline Synthetic oil MIDEL (SO) & $35.12^{* *}$ \\
\hline Vegetable oil FR3 (VO) & 39 \\
\hline $20 \% \mathrm{VO}+80 \% \mathrm{MO}$ & $33.48^{*}$ \\
\hline $50 \% \mathrm{VO}+5 \mathrm{O} \% \mathrm{MO}$ & $26.23^{* *}$ \\
\hline \multirow{2}{*}{$80 \% \mathrm{VO}+20 \% \mathrm{MO}$} & $47.97^{*}$ \\
\hline $20 \% \mathrm{SO}+80 \% \mathrm{MO}$ & $60.56^{*}$ \\
\hline $50 \% \mathrm{SO}+5 \mathrm{O} \% \mathrm{MO}$ & $75.13^{* *}$ \\
\hline \multirow{2}{*}{$80 \% \mathrm{SO}+20 \% \mathrm{MO}$} & $50.20^{*}$ \\
\hline
\end{tabular}

\subsection{Test Cell and Its Filling}

Breakdown voltage testing was achieved on a test cell of $400 \mathrm{~mL}$ BAUR Dieltest (BAUR GmbH, Sulz, Austria) containing two brass sphere electrodes of $12.5 \mathrm{~mm}$ diameter, arranged horizontally, with a gap of $2.50 \pm 0.05 \mathrm{~mm}$ according to the IEC 60156 Standard [5]. Before each series of measurements, the test cell and electrodes were polished using an abrasive cloth and cleaned with ethanol, followed by washing with hot water at a temperature of $60-80{ }^{\circ} \mathrm{C}$ and drying using an oven at a temperature of $90^{\circ} \mathrm{C}$ for $1 \mathrm{~h}$.

\subsection{Voltage Sources and Tests Procedure}

AC voltage was supplied by a 200kV-50Hz-60kVA transformer (Haefely Hypotronics, Basel, Switzerland) and measurement of breakdown voltage was conducted according to standard specifications IEC 60156 [5]. The voltage was applied without interruption from zero to breakdown with a rate of $2 \pm 0.2 \mathrm{kV} / \mathrm{s}$. Each sample was tested with a series of 40 times to meet the amount of tests required by statistical analysis. Note that this amount of testing is more than the amount requested by the standard IEC 60156 of 24 times.

Note that the time required to allow the gas bubbles formed in the liquid to breakdown depends on the viscosity of oil: the higher the viscosity, the longer the time. Since the viscosity of mineral oil is lower than that of ester oil, the rest time between two successive tests of the latter should be longer than for mineral oil: $15 \mathrm{~min}$ for natural esters [6] versus $5 \mathrm{~min}$ for mineral oils [5]. However, due to 
the comparative study, and in order to work under the same conditions, the same waiting time was applied for all types of oils and mixtures: a waiting period of $30 \mathrm{~min}$ between the filling of the test cell and the first measurement and a rest period of $10 \mathrm{~min}$ with agitation of oil between each measurement.

A 200kV-2mA high voltage generator (Spellman type, Spellman ${ }^{R}$ type, High Voltage Electronics Corporation, New York, NY, USA) delivering a positive DC voltage was used. The applied DC voltage was increased from zero to breakdown according to the step method as described in Figure 1. Each voltage level was applied for a duration $\Delta t=1 \mathrm{~min}$. The value of the step $\Delta U$ is a function of the value of the applied voltage: (1) in the range $0-40 \mathrm{kV}, \Delta U=5 \mathrm{kV}$; and (2) for voltage above $40 \mathrm{kV}, \Delta U=2 \mathrm{kV}$. The breakdown voltage is the average value over a series of 20 measurements. A rest period of $10 \mathrm{~min}$ with agitation of oil was adopted between two consecutives measurements.

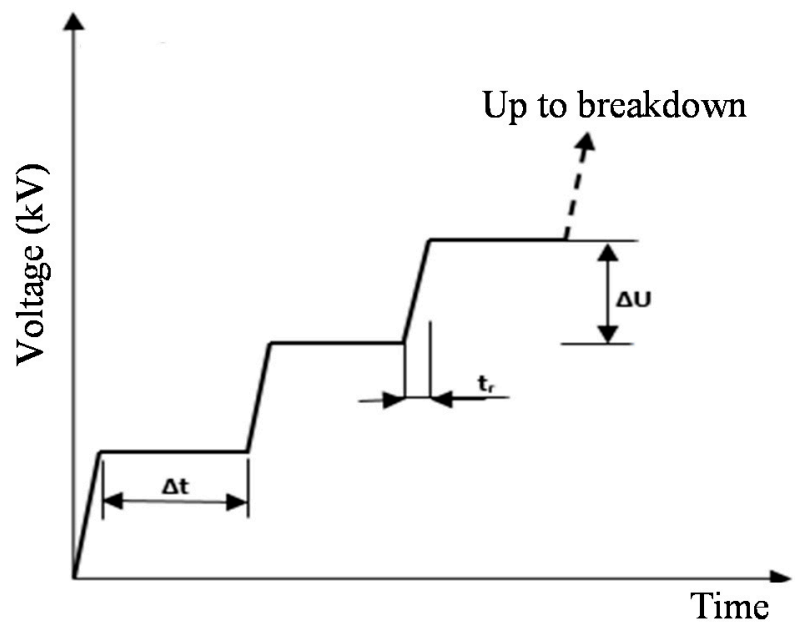

Figure 1. DC test procedure.

\section{Experimental Results}

\subsection{Comparison of Breakdown Voltages of Oils Alone}

\subsubsection{Histograms of Breakdown Voltage}

Figures 2 and 3 give the values of breakdown voltages (BDV) measured under AC and DC voltages, respectively. These values are distributed around a mean (average) value. One notes that the highest values for vegetable oil appear at the beginning of the measuring series; this phenomenon is less present in synthetic ester and mineral oil. In addition, the DC breakdown voltage of mineral oil tends to increase as the end of the test series approaches. The histograms of the distribution of BDV of the tested insulating oils are shown in Figure 4; such a representation allows us to detect eventual anomalies in the distribution of BDV in different ranges of voltages. It can be observed that the breakdown voltages of mineral oil are lower than those of synthetic and natural esters. In AC as in DC voltages, mineral oil has the lowest breakdown voltage: this can be explained by its very high water content (>10 ppm).

Note that the mean value of breakdown voltage, $U_{\text {mean }}$, is computed using the following equation

$$
U_{\text {mean }}=\sum_{1}^{n} \frac{U_{i}}{n}
$$

where $U_{i}$ is the measured breakdown voltage of test $i$ and $n$ the number of measurements of the series. 


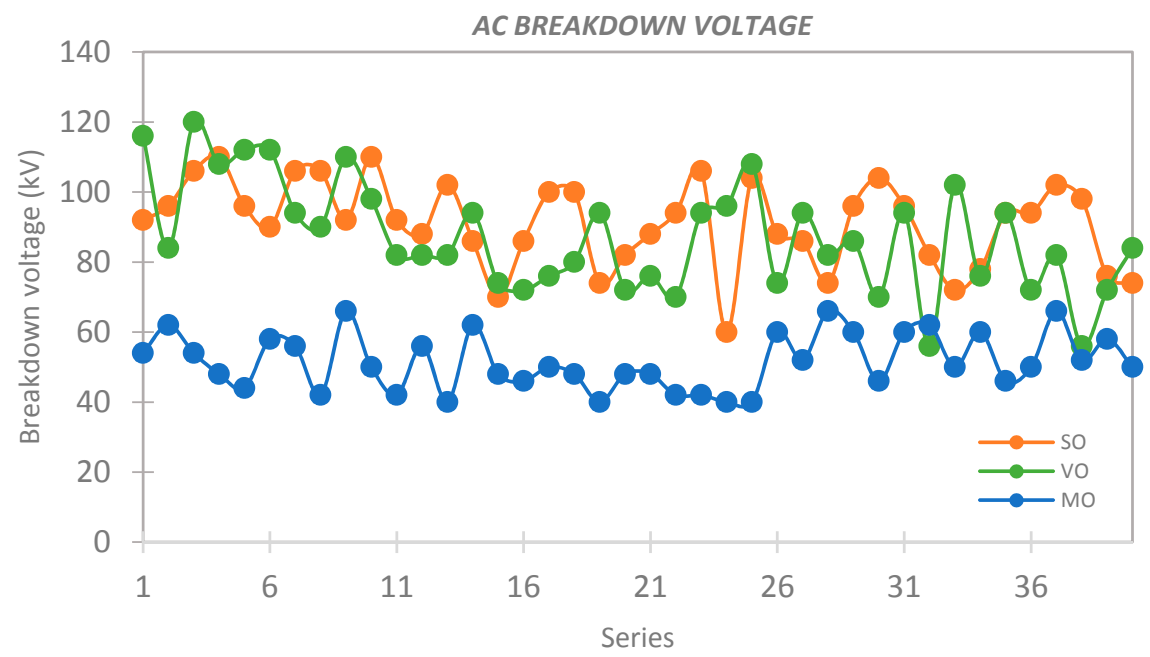

Figure 2. Distribution of AC breakdown voltages of mineral oil (MO), vegetable oil (VO), and synthetic oil (SO).

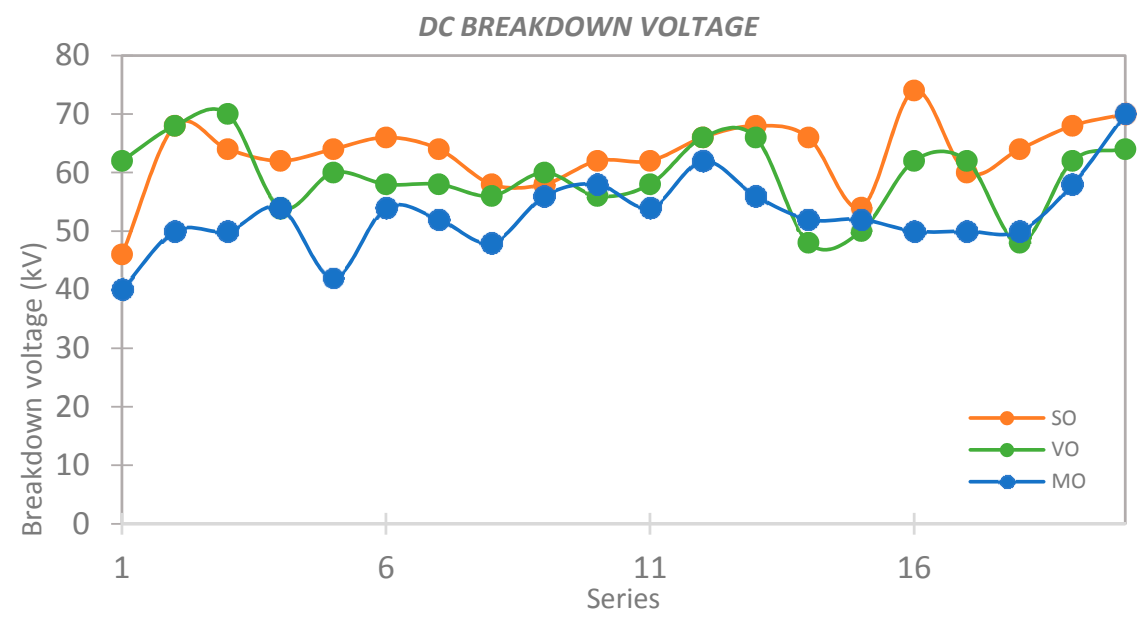

Figure 3. Distribution of DC breakdown voltages of mineral oil (MO), vegetable oil (VO), and synthetic oil (SO).
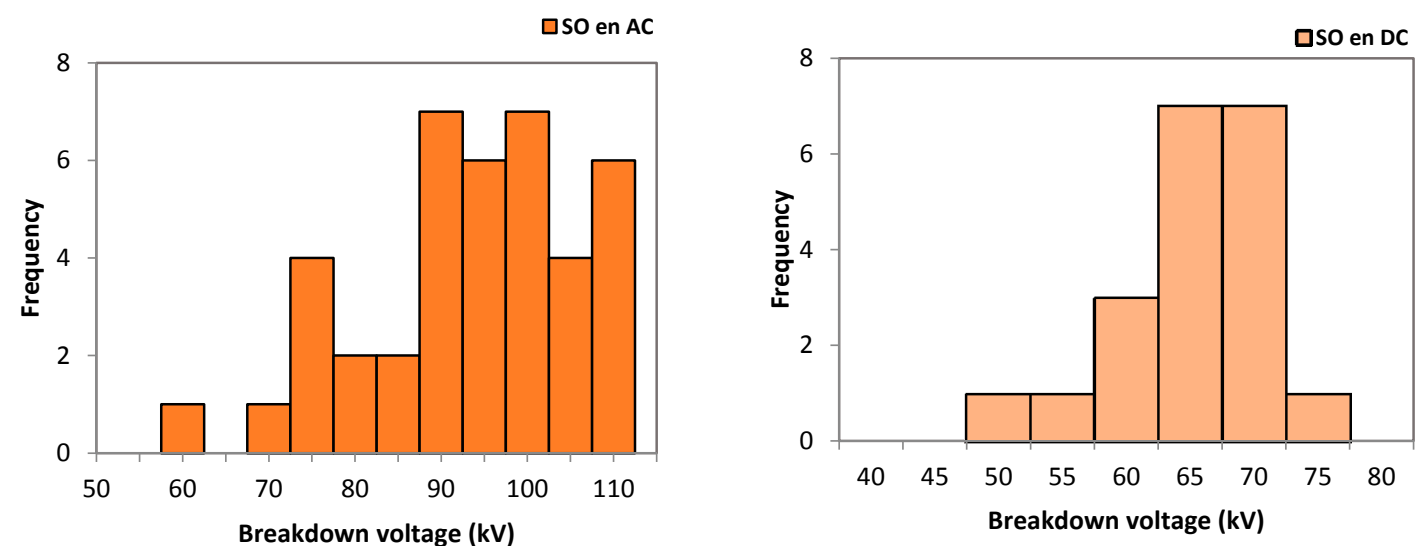

Figure 4. Cont. 

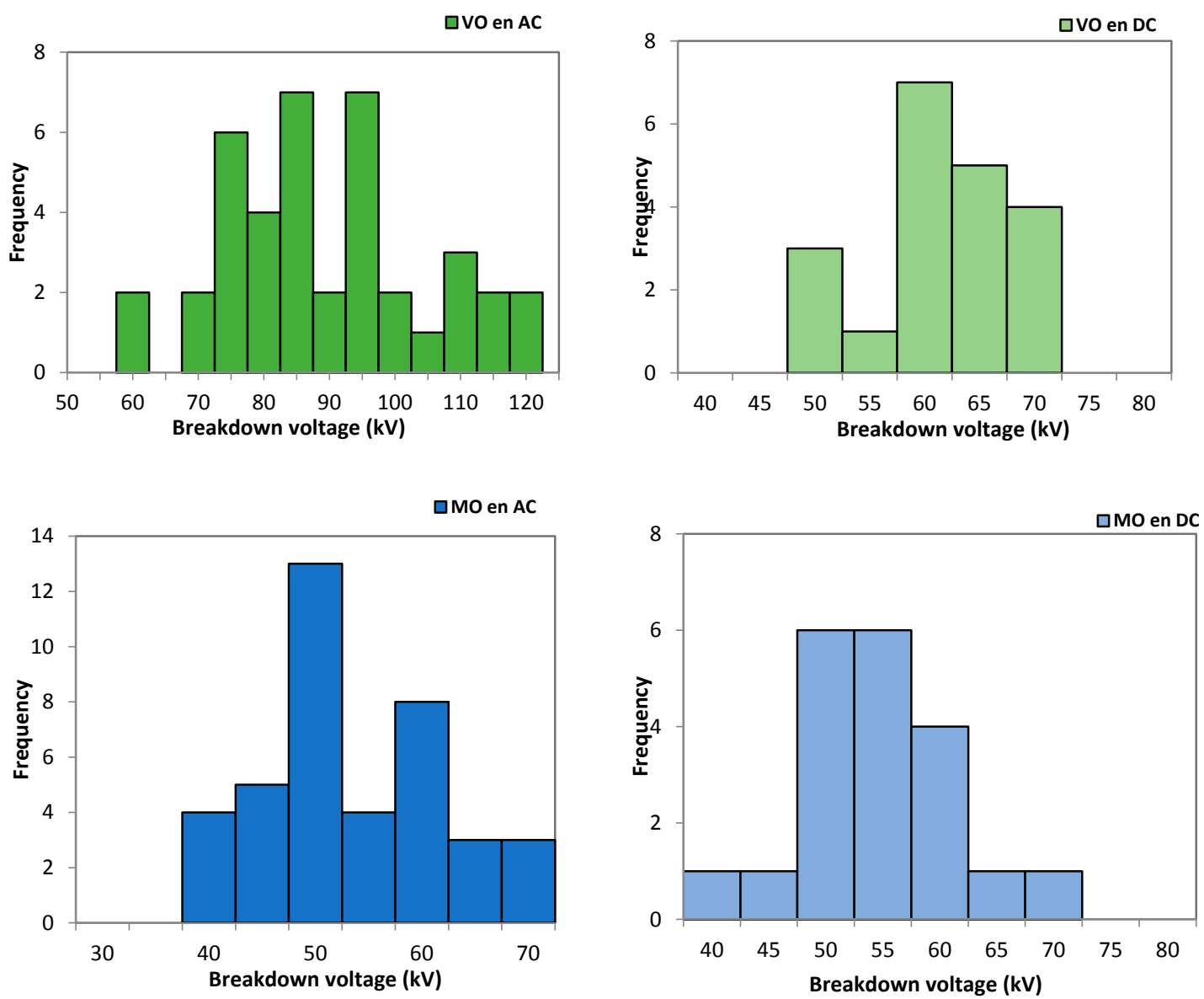

Figure 4. Histograms of AC and DC breakdown voltages of oils alone.

The values of the average breakdown voltage always follow the same order from the highest to the smallest for both voltage waveforms: first synthetic oil, then natural ester, and finally mineral oil (Figure 5). It can be noted that the breakdown voltage depends strongly on the waveform of the applied voltage: it is markedly higher in AC than in DC for ester oils. This difference can be explained by the application time of the voltage which is longer for DC. On the other hand, as regards mineral oil, the breakdown voltage varies very little depending on the shape of the applied voltage.

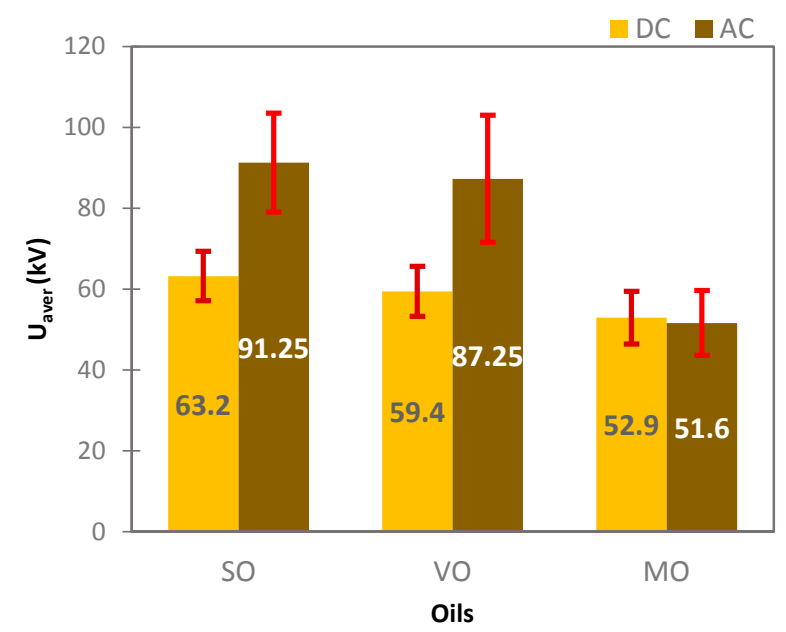

Figure 5. Average breakdown voltage of oils alone; the bars indicate the standard deviation. 
The standard deviation represents the dispersion of the breakdown voltage measured with respect to its mean value. Also, vegetable oil with the highest standard deviation implies that breakdown can occur at a very distant voltage value (greater or smaller) than its mean value.

\subsubsection{Hypothesis Test and Statistical Analysis of Breakdown Voltages}

For the statistical analysis of BDV probability, we first applied a hypothesis test to identify the distribution that the experimental data follow. In this study, we used Normal and Weibull distributions with a significance level of test $\alpha$ of $5 \%(\alpha=0.05)$. Normal and Weibull distribution hypothesis tests were performed by Shapiro Wilk [7] and Anderson-Darling tests, respectively [8]. Other criteria were also used to check the results of the hypothesis test [9]. All computations of the hypothesis test were carried out using software $\mathrm{R}[10]$. The hypotheses null $\left(\mathrm{H}_{0}\right)$ and alternative $\left(\mathrm{H}_{1}\right)$ are:

- $\mathrm{H}_{0}$ : the breakdown voltages measured follow the distribution Normal (resp. Weibull);

- $\mathrm{H}_{1}$ : the breakdown voltages measured do not follow the normal distribution (resp. Weibull).

To identify the distribution law that the experimental data follow one computes the $p$-value that is the probability of making an error if the null hypothesis is rejected. In case the $p$-value is greater than $\alpha$, the null hypothesis is accepted, and the data then follow a statistical law. Tables 3-6 summarize the compliance hypothesis test results.

Table 3. Hypothesis test of conformity to normal distribution of oils alone in AC.

\begin{tabular}{cccc}
\hline Oil & W & $\boldsymbol{p}$-Value & Conformity to Normal Distribution \\
\hline SO & 0.9549 & 0.2026 & Yes \\
VO & 0.9593 & 0.2793 & Yes \\
MO & 0.9310 & 0.0276 & No \\
\hline
\end{tabular}

Table 4. Hypothesis test of conformity to Weibull distribution of oils alone in AC.

\begin{tabular}{cccc}
\hline Oil & A & $p$-Value & Conformity to Weibull Distribution \\
\hline SO & 0.2464 & 0.6591 & Yes \\
VO & 1.0485 & 0.0078 & No \\
MO & 1.4527 & 0.0008 & No \\
\hline
\end{tabular}

Table 5. Hypothesis test of conformity to normal distribution of oils alone in DC.

\begin{tabular}{cccc}
\hline Oil & W & $\boldsymbol{p}$-Value & Conformity to Normal Distribution \\
\hline SO & 0.9277 & 0.1796 & Yes \\
VO & 0.9599 & 0.5099 & Yes \\
MO & 0.9369 & 0.2738 & Yes \\
\hline
\end{tabular}

Table 6. Hypothesis test of conformity to Weibull distribution of oils alone in DC.

\begin{tabular}{cccc}
\hline Oil & A & $\boldsymbol{p}$-Value & Conformity to Weibull Distribution \\
\hline SO & 0.4073 & 0.3215 & Yes \\
VO & 0.2111 & 0.7283 & Yes \\
MO & 0.8656 & 0.0213 & No \\
\hline
\end{tabular}

With the exception of mineral oil, the breakdown voltage of ester oils conforms to the normal distribution irrespective of the shape of the applied voltage. In DC, for the Weibull law, the null hypothesis is accepted for ester oils, but only for synthetic ester in AC. Similar results have been reported by others [11]. Therefore, we chose the Normal law for the statistical study. The probability 
of the breakdown voltage of tested oils is given in Figures 6 and 7. We note that under AC, synthetic oil better follows the normal distribution with respect to vegetable oil. Furthermore, at low probability, the breakdown voltages of natural ester are lower than the adjustment curve. In DC, the breakdown voltage at low and high probabilities lies far from the adjustment curve for all types of oils.

The coefficients of asymmetry (skewness) and flattening (kurtosis) were calculated in order to observe the variations between the statistical values and the real values (Figure 8). The asymmetry coefficient makes it possible to check if the distribution of BDV is more or less asymmetrical. For a Normal distribution it is equal to 0 . Whatever the electrical constraint (DC or AC), the asymmetry coefficient of synthetic ester is negative. This means that the distribution presents an asymmetry to the left, i.e., the majority of values are concentrated to the right of the mean value. For vegetable oil, this coefficient is positive in AC and negative in DC.

The coefficient of flattening of a normal distribution is 3; it measures the degree of crushing of the distribution. In AC, this coefficient is less than 3 for ester oils; these distributions are then called platikurtic, i.e., they have wider peaks than that of a normal distribution, and therefore the values of BDV are dispersed around the mean value. In addition, the probabilities of extreme values are lower than those of a normal distribution. With the exception of natural ester which maintains a continuous flattening coefficient of less than 3 , the tetra-esters and the mineral oils have a coefficient greater than 3 . In this case, the measured values of BDV are mainly concentrated around the mean value; the distribution presents a sharper peak and thicker tails than those of a normal distribution.

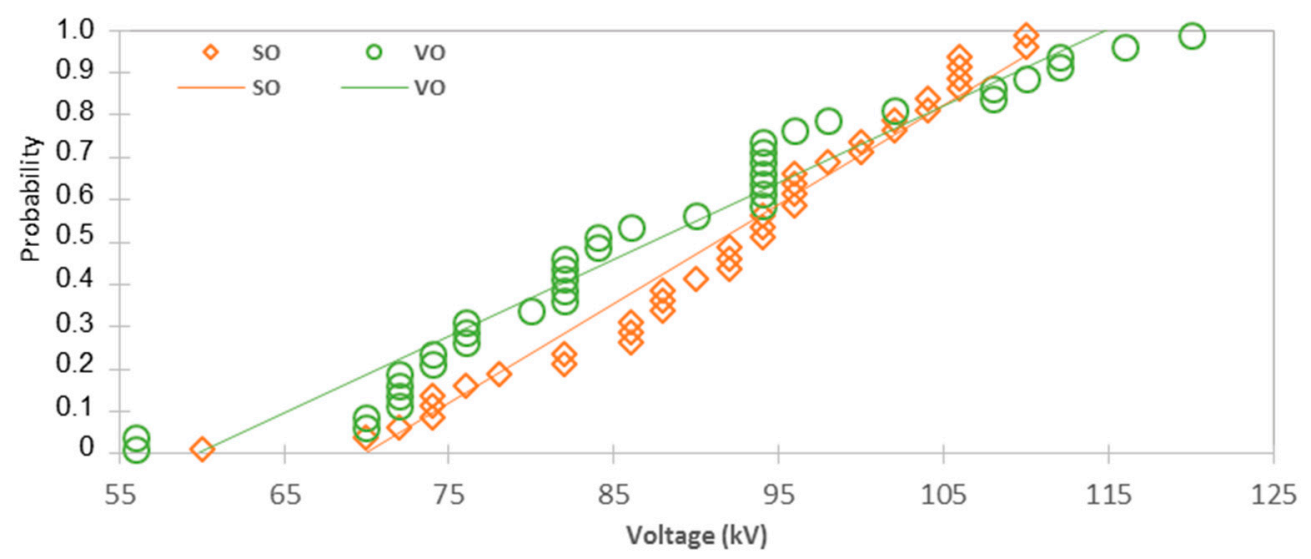

Figure 6. Probability of normal distribution of AC breakdown voltage of oils alone.

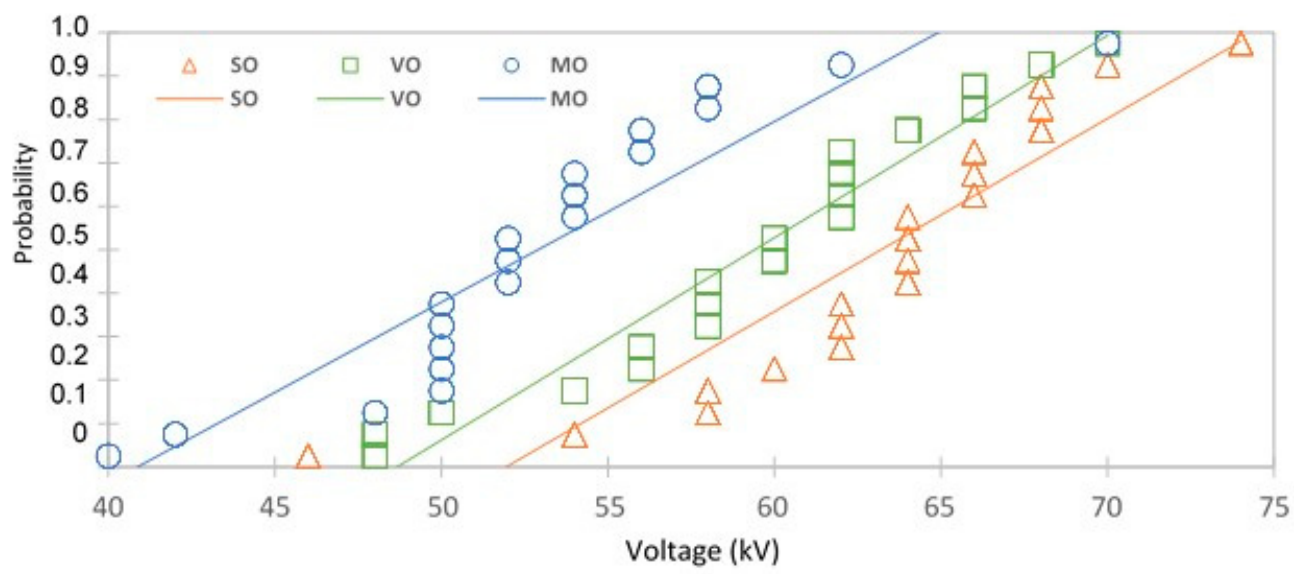

Figure 7. Probability of normal distribution of DC breakdown voltage of oils alone. 
We used the conformance to the normal distribution to compute BDV probabilities U1\%, U10\%, and $U 50 \%$ that are the breakdown voltages for the 1\%,10\%, and 50\% probability risk levels (Figure 9). Calculating the low probability voltage (1\%) makes it possible to determine a safety coefficient when designing electrical equipment. The standard deviation (std) represents the dispersion of BDV with respect to its mean. The higher the standard deviation, the more dispersed is BDV.

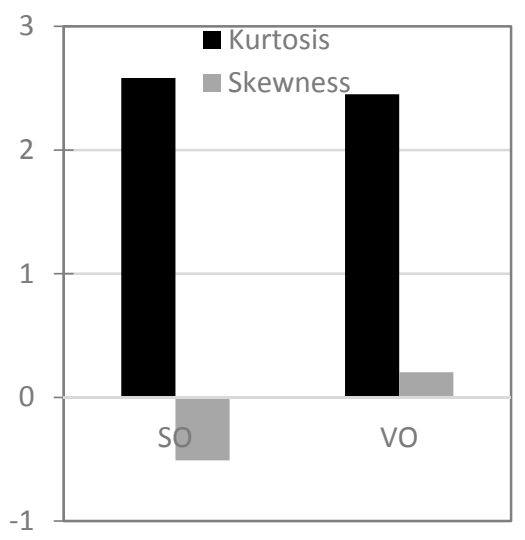

(a)

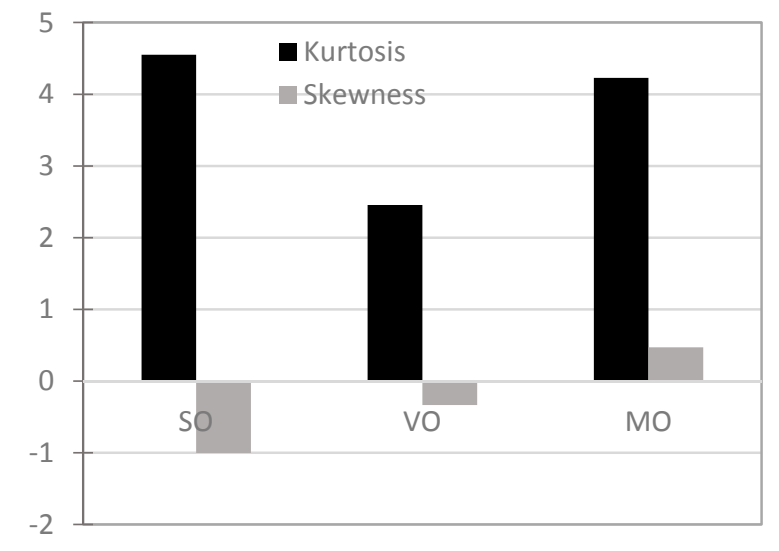

(b)

Figure 8. Coefficients of asymmetry and flattening of the normal distribution of AC (a) and DC (b) breakdown voltages of oils.

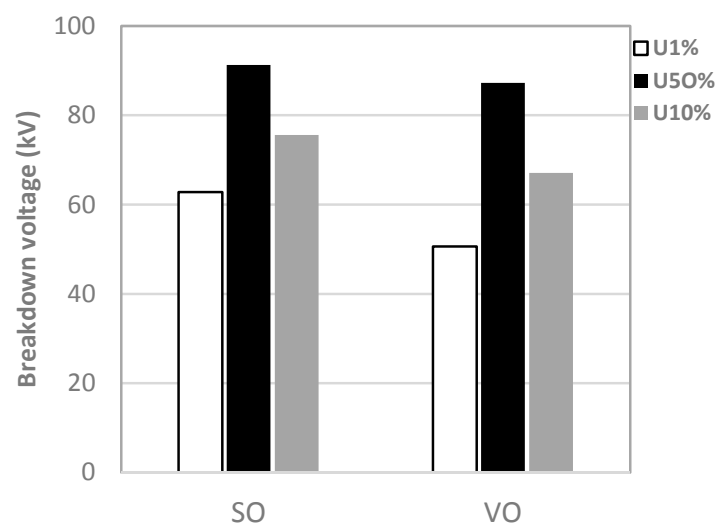

(a)

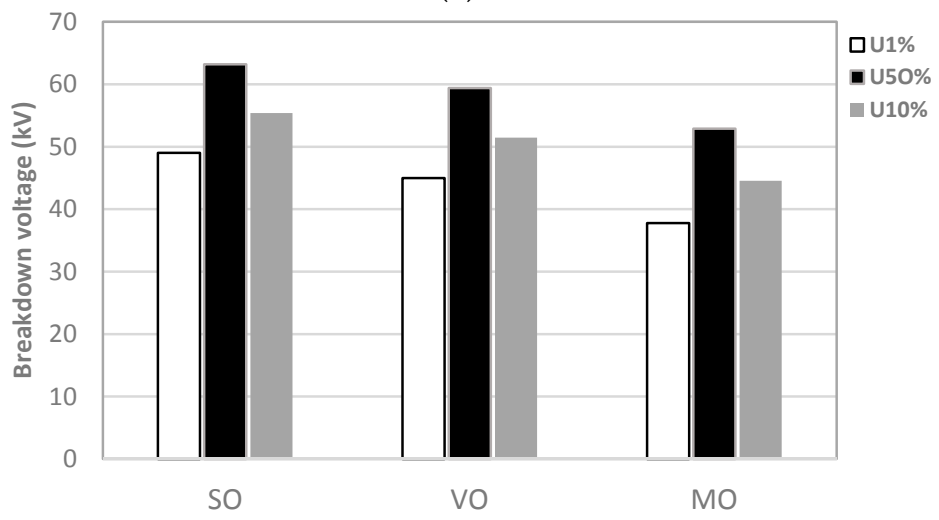

(b)

Figure 9. Probability of AC (a) and DC (b) breakdown voltages of oils alone. 
Note that for the risk levels of $1 \%, 10 \%$, and $50 \%$ probability, synthetic ester has the highest breakdown voltages, followed by vegetable oil and finally mineral oil.

The above experimental results show that whatever the shape of the applied voltage (DC or AC), the dielectric strength of ester oils (natural and synthetic) is always better than that of mineral oil. Indeed, the good solubility of water in esters makes them very insensitive to moisture in contrast to mineral oil. Moreover, the breakdown voltage is a function of the shape and time duration of the stress application. In DC, it is considerably less than that measured under AC.

It is important to note that the dielectric strength is not defined by a single value of the breakdown voltage but rather by a range of values, and this range of values is more extensive for vegetable oil and more reduced for mineral oil. Moreover, the values obtained under DC are always more concentrated around the mean value, whereas an inverse result is recorded in AC, where they are fairly dispersed (far from the mean value).

As in other studies, we came to the conclusion, through statistical analysis, that the breakdown voltage of oils generally follows a normal distribution.

\subsection{Comparison of Breakdown Voltages of Oil Mixtures}

\subsubsection{Histograms of Breakdown Voltage}

a. Mineral oil/natural ester mixtures

Figures 10 and 11 depict the distribution of BDV of mineral (MO)/vegetable oil (VO) mixtures under AC and DC, respectively. It is of note that the highest BDV is obtained with the mixture of $20 \%$ natural ester and $80 \%$ mineral oil, which also corresponds to the highest voltage of vegetable oil alone. Moreover, it can be observed that the smallest breakdown voltage value of the various mixtures always remains higher than the highest value of that of mineral oil alone.

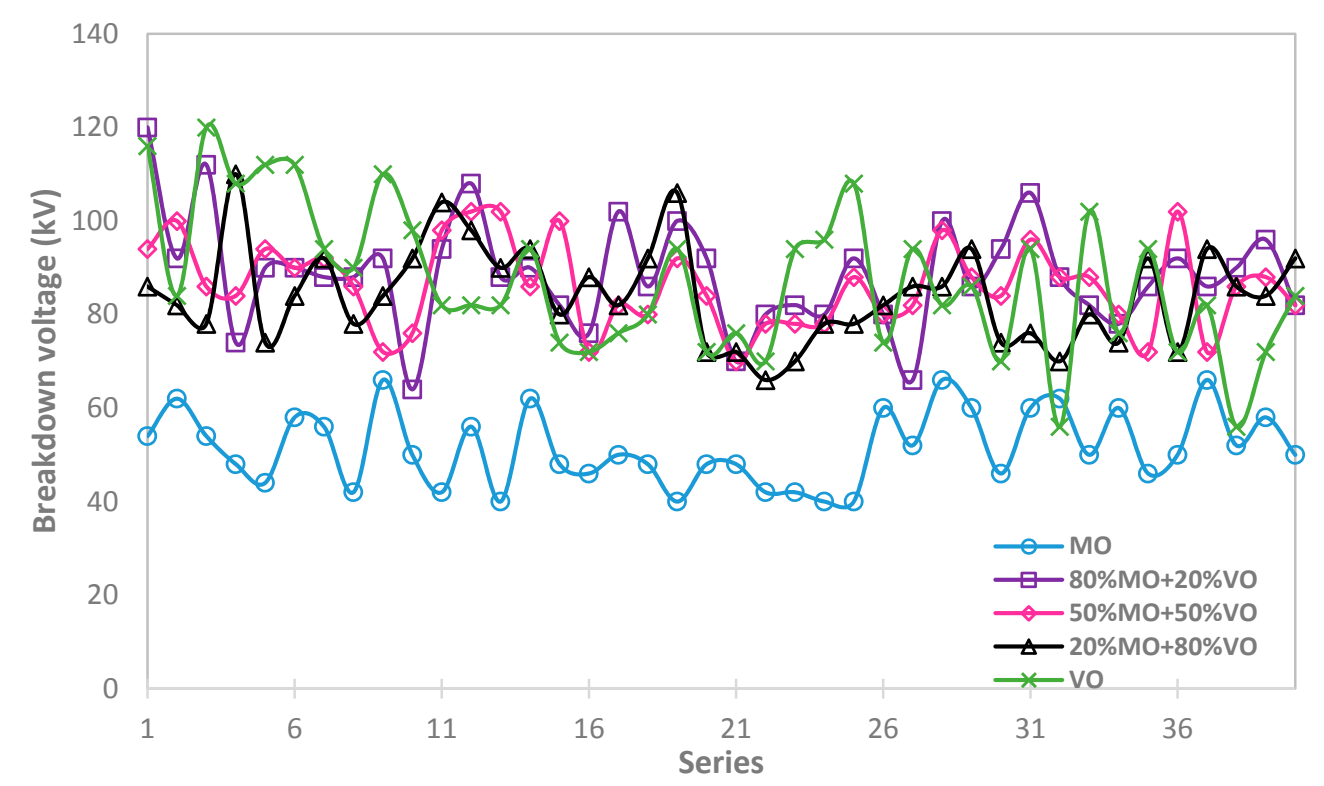

Figure 10. Distribution of breakdown voltages under AC of mineral (MO)/vegetable oil (VO) mixtures. 


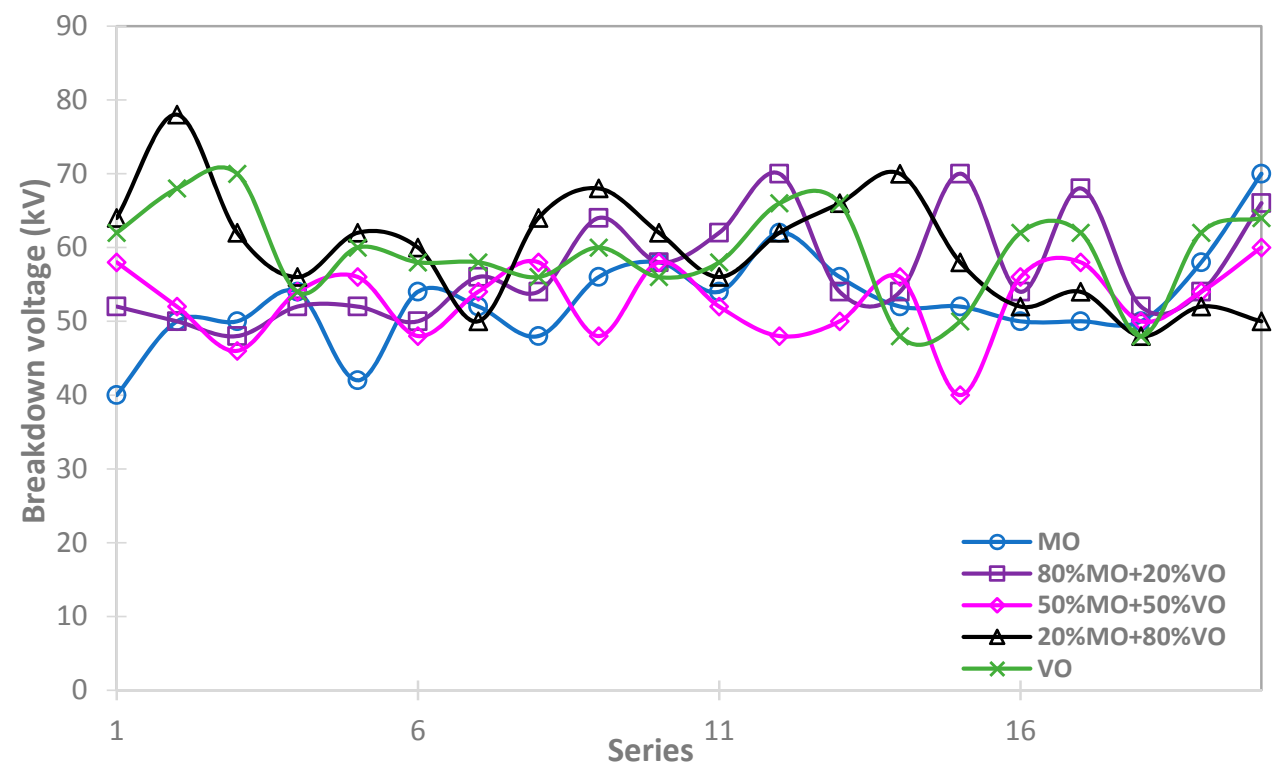

Figure 11. Distribution of breakdown voltages under DC of mineral (MO)/vegetable oil (VO) mixtures.

The cumulative frequency breakdown probability curves of the various mixtures with vegetable oil are given in Figures 12 and 13. One observes from the trend curves, that the addition of natural ester in mineral oil considerably modifies its breakdown voltage in AC and DC except for the mixture at the 50:50 ratio under DC stress which exhibits a behavior very similar to that of mineral oil alone.

In DC, the addition of $20 \%$ natural ester gives moderate values of BDV, between those of the two mineral and vegetable oils alone. The $80 \%$ mixture exhibits a dielectric strength very close to that of the vegetable oil alone.

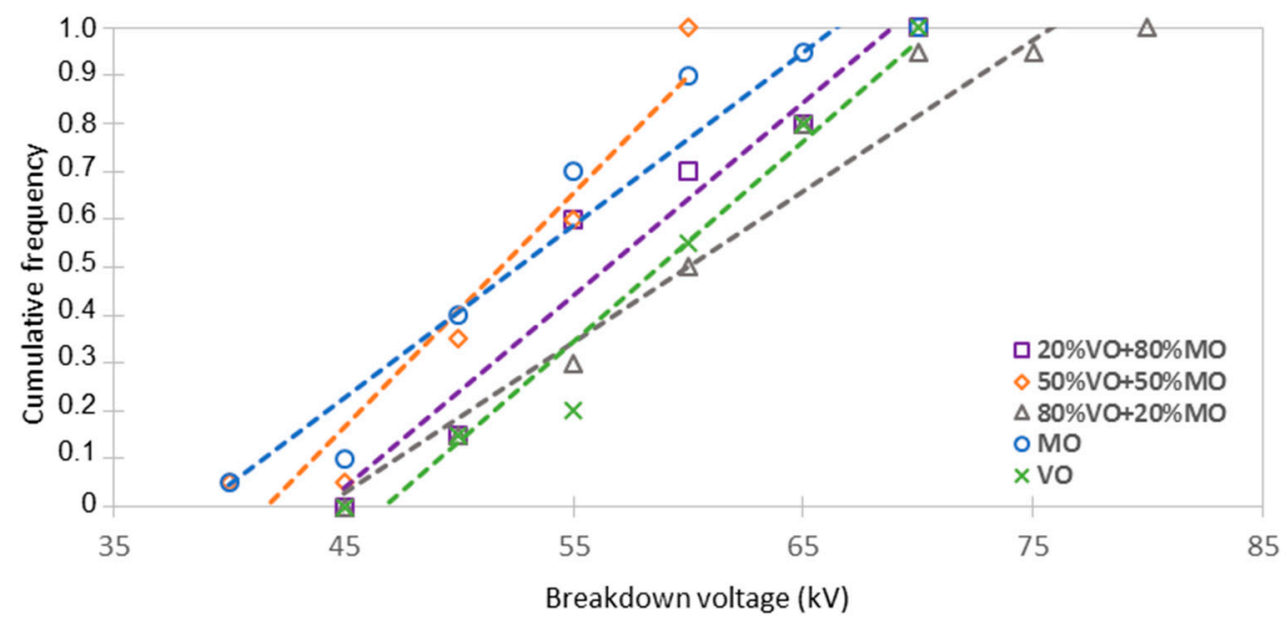

Figure 12. Linear trend of the cumulative frequency of DC breakdown voltage of mineral oil and natural ester mixtures.

Under DC voltage, it should be noted that the behavior of the three tested oil mixtures is similar to that of vegetable oil alone: the characteristic of natural ester oil predominates over that of mineral oil.

The above remarks were confirmed by the calculation of the mean values of the breakdown voltage of the various samples as shown in Figure 14. 


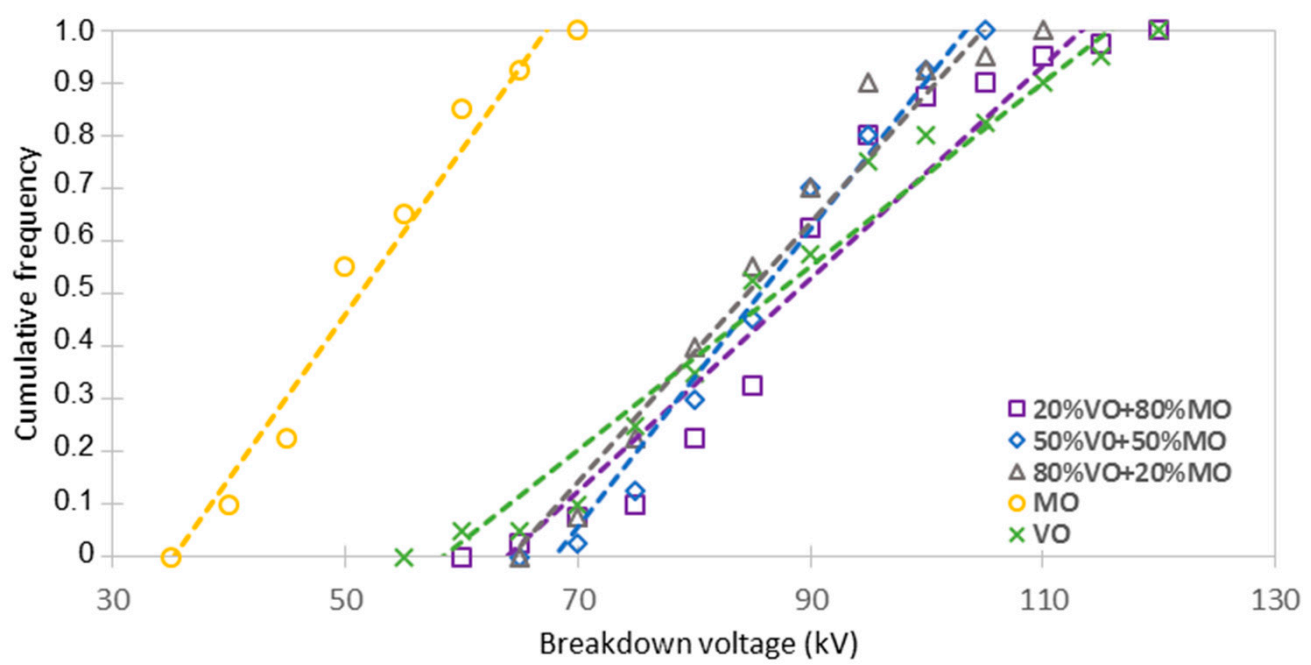

Figure 13. Linear trend of the cumulative frequency of AC breakdown voltage of mineral oil and natural ester mixtures.

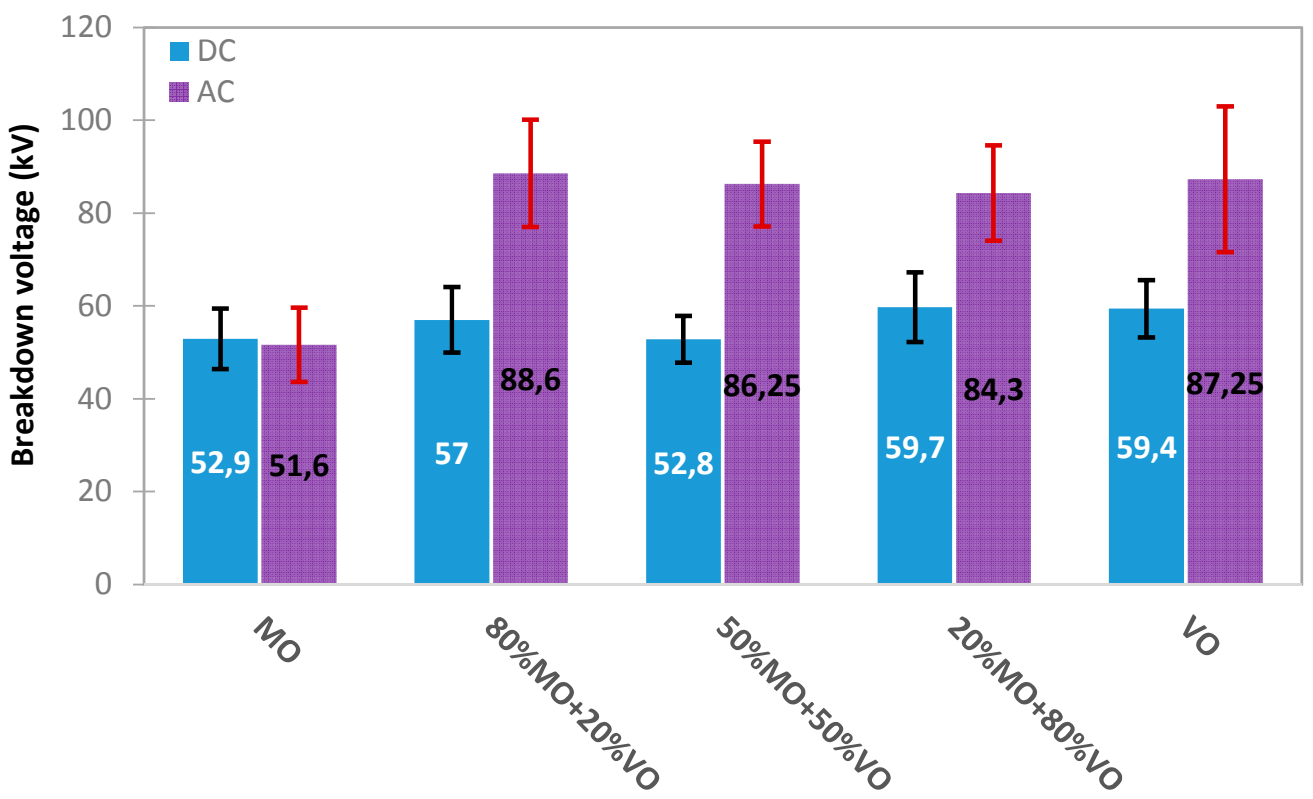

Figure 14. Average breakdown voltage of mineral oil and natural ester oil mixtures; the bars indicate the standard deviation.

\section{b. Mineral oil/synthetic ester mixtures}

Figures 15 and 16 depict the distribution of BDV of mineral (MO)/Synthetic oil (SO) mixtures under $\mathrm{AC}$ and $\mathrm{DC}$, respectively. The highest breakdown voltage is obtained with a mixture at $50 \%$. In $\mathrm{AC}$, the smallest value of this mixture remains higher than the highest value of mineral oil alone.

The breakdown voltage of mixtures is always better than that of mineral oil alone whether it is in DC or in AC. It is also of note that the $50 \%$ mixture exhibits the highest breakdown voltage, which is closest to synthetic oil alone. This voltage is slightly higher than that of synthetic oil under AC stress. The $20 \%$ and $80 \%$ mixtures have a similar dielectric strength (Figures 17 and 18). 


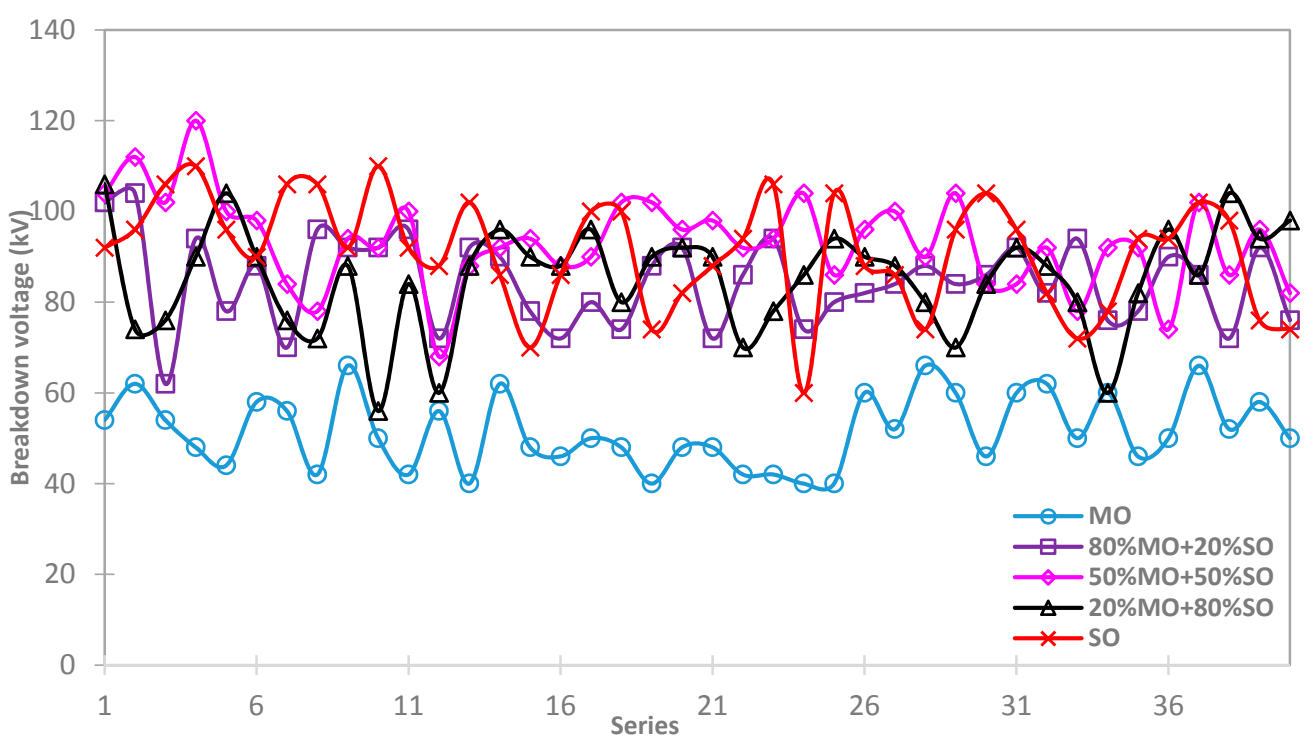

Figure 15. Distribution of breakdown voltages under AC of mineral (MO)/Synthetic oil (SO) mixtures.

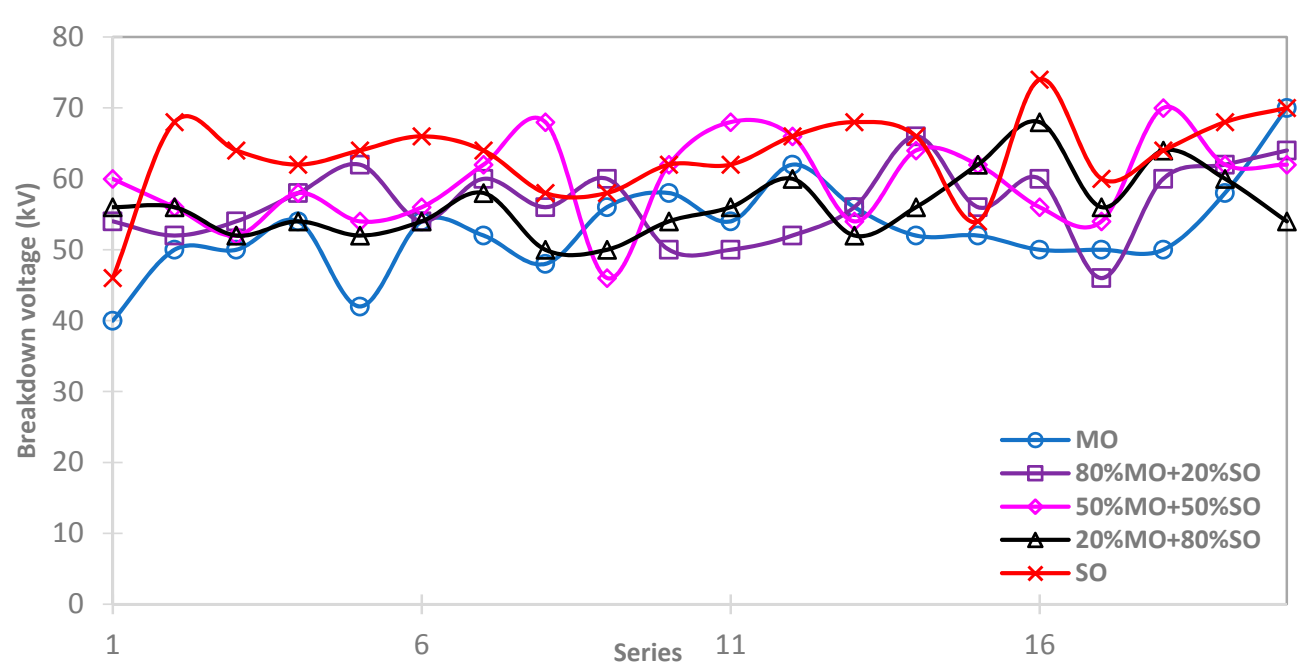

Figure 16. Distribution of breakdown voltages under DC of mineral (MO)/Synthetic oil (SO) mixtures.

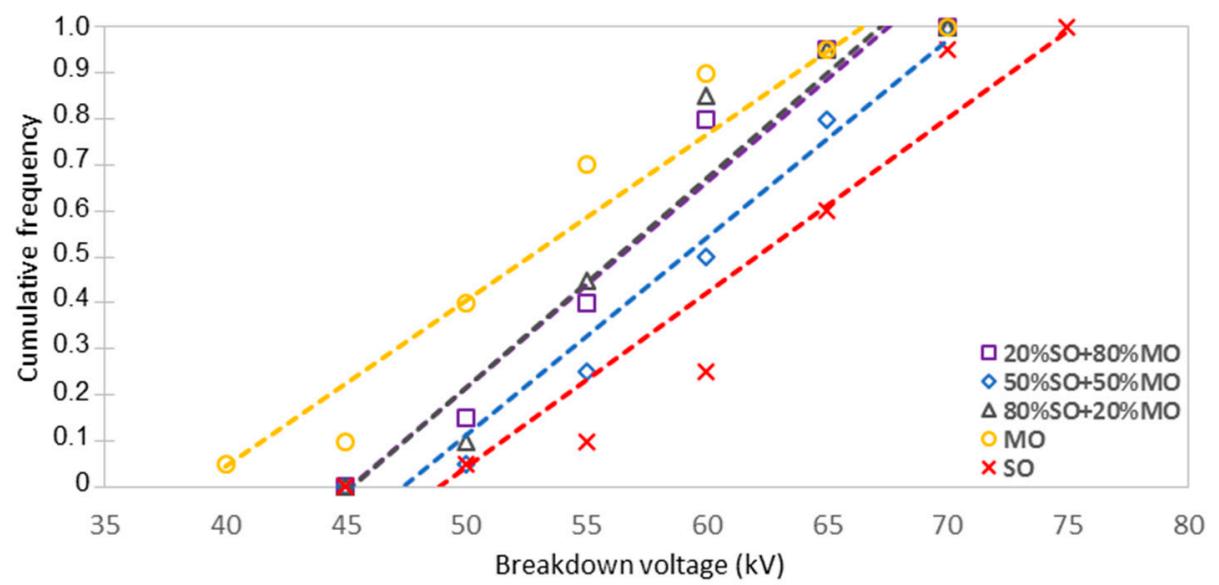

Figure 17. Linear trend of the cumulative frequency of DC breakdown voltage of mineral oil and synthetic ester mixtures. 


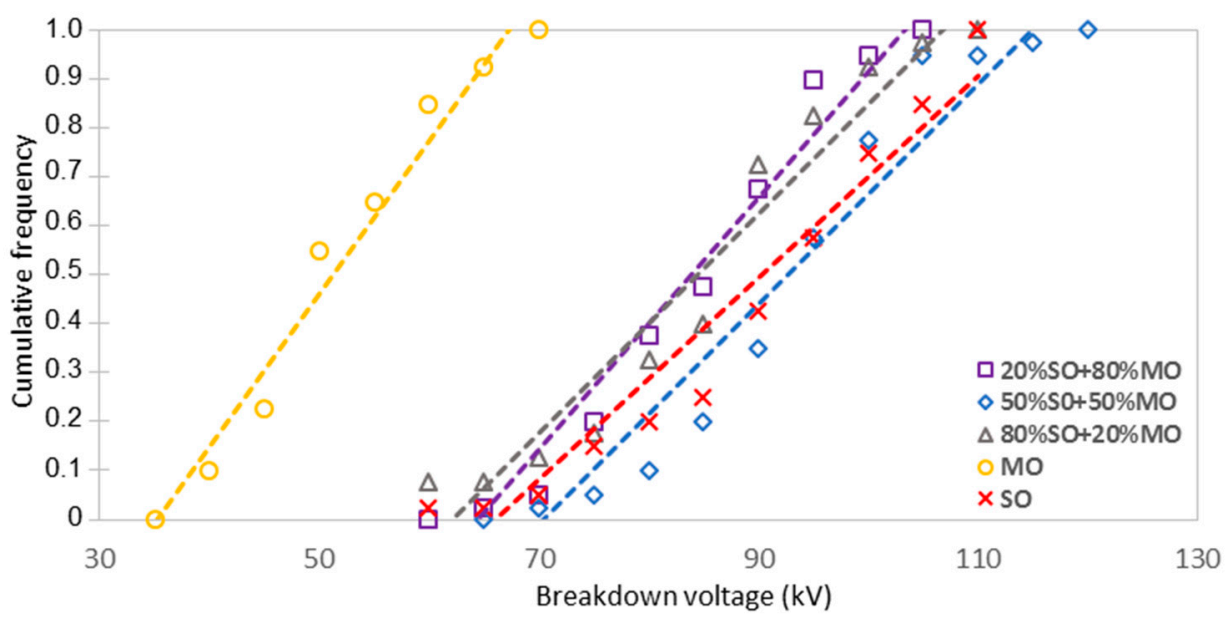

Figure 18. Linear trend of the cumulative frequency of AC breakdown voltage of mineral oil and natural ester mixtures.

The mean values of the breakdown voltage of mixtures are shown in Figure 19. In AC, while the mixture with only $20 \%$ synthetic ester is sufficient to considerably improve mineral oil, the mixture at $80 \%$ deteriorates that of synthetic oil. In DC, the variations in breakdown voltage between oils remain fairly moderate.

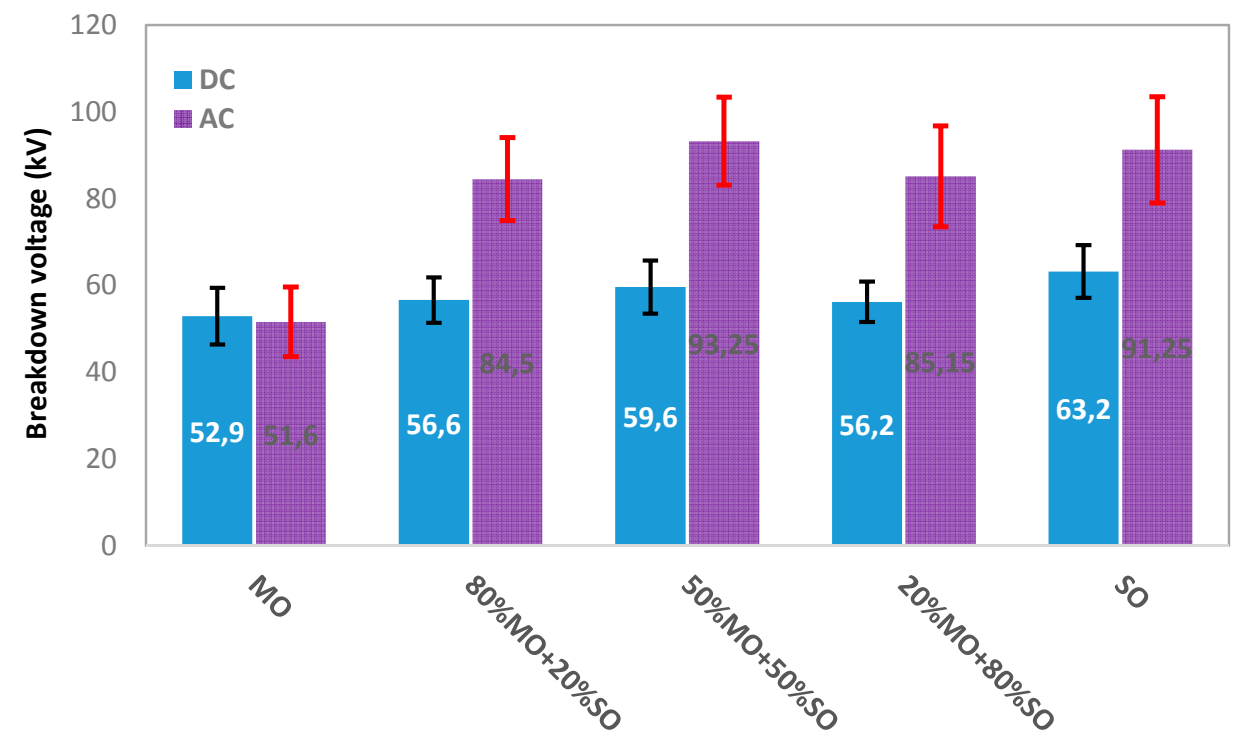

Figure 19. Average breakdown voltage of mineral oil and synthetic ester oil mixtures; the bars indicate the standard deviation.

\subsubsection{Statistical Analysis of Mixtures}

The analysis of the conformity to the normal and Weibull distributions of BDV of the different mixtures, by taking into account the previously stated points (hypothesis test, value of $\alpha$ ), is summarized in Tables 7-10.

It can be noted that the mixtures follow above all a normal distribution whether they are in DC or AC. The fact of whether oil alone follows a statistical law or not does not influence the conformity of the mixture. It is for example, under DC stress, the case of mineral and vegetable oils, which alone follow a normal law, contrary to the case of a mixture with $20 \%$ ester oil. 
Table 7. Hypothesis test of conformity to normal distribution of oil mixtures in AC.

\begin{tabular}{cccc}
\hline Oil Mixtures & W & $p$-Value & Conformity to Normal Distribution \\
\hline $20 \% \mathrm{VO}+80 \% \mathrm{MO}$ & 0.973 & 0.533 & Yes \\
$50 \% \mathrm{VO}+50 \% \mathrm{MO}$ & 0.951 & 0.142 & Yes \\
$80 \% \mathrm{VO}+20 \% \mathrm{MO}$ & 0.964 & 0.372 & Yes \\
$20 \% \mathrm{SO}+80 \% \mathrm{MO}$ & 0.971 & 0.484 & Yes \\
$50 \% \mathrm{SO}+50 \% \mathrm{MO}$ & 0.984 & 0.870 & Yes \\
$80 \% \mathrm{SO}+20 \% \mathrm{MO}$ & 0.950 & 0.119 & Yes \\
\hline
\end{tabular}

Table 8. Hypothesis test of conformity to Weibull distribution of oil mixtures in AC.

\begin{tabular}{cccc}
\hline Oil Mixtures & A & $p$-Value & Conformity to Weibull Distribution \\
\hline $20 \% \mathrm{VO}+80 \% \mathrm{MO}$ & 1,022 & 0.009 & No \\
$50 \% \mathrm{VO}+50 \% \mathrm{MO}$ & 1,044 & 0.007 & No \\
$80 \% \mathrm{VO}+20 \% \mathrm{MO}$ & 1,188 & 0.003 & No \\
$20 \% \mathrm{SO}+80 \% \mathrm{MO}$ & 0,484 & 0.217 & Yes \\
$50 \% \mathrm{SO}+50 \% \mathrm{MO}$ & 0,444 & 0.271 & Yes \\
$80 \% \mathrm{SO}+20 \% \mathrm{MO}$ & 0,413 & 0.320 & Yes \\
\hline
\end{tabular}

Table 9. Hypothesis test of conformity to normal distribution of oil mixtures in DC.

\begin{tabular}{cccc}
\hline Oil Mixtures & W & $p$-Value & Conformity to Normal Distribution \\
\hline $20 \% \mathrm{VO}+80 \% \mathrm{MO}$ & 0.862 & 0.006 & No \\
$50 \% \mathrm{VO}+50 \% \mathrm{MO}$ & 0.935 & 0.257 & Yes \\
$80 \% \mathrm{VO}+20 \% \mathrm{MO}$ & 0.962 & 0.570 & Yes \\
$20 \% \mathrm{SO}+80 \% \mathrm{MO}$ & 0.977 & 0.879 & Yes \\
$50 \% \mathrm{SO}+50 \% \mathrm{MO}$ & 0.965 & 0.633 & Yes \\
$80 \% \mathrm{SO}+20 \% \mathrm{MO}$ & 0.921 & 0.116 & Yes \\
\hline
\end{tabular}

Table 10. Hypothesis test of conformity to Weibull distribution of oil mixtures in DC.

\begin{tabular}{cccc}
\hline Oil Mixtures & A & $p$-Value & Conformity to Weibull Distribution \\
\hline $20 \% \mathrm{VO}+80 \% \mathrm{MO}$ & 2.666 & $1.1 \times 10^{-6}$ & No \\
$50 \% \mathrm{VO}+50 \% \mathrm{MO}$ & 0.310 & 0.510 & Yes \\
$80 \% \mathrm{VO}+20 \% \mathrm{MO}$ & 0.494 & 0.198 & Yes \\
$20 \% \mathrm{SO}+80 \% \mathrm{MO}$ & 0.301 & 0.530 & Yes \\
$50 \% \mathrm{SO}+50 \% \mathrm{MO}$ & 0.380 & 0.368 & Yes \\
$80 \% \mathrm{SO}+20 \% \mathrm{MO}$ & 1.525 & 0.0004 & No \\
\hline
\end{tabular}

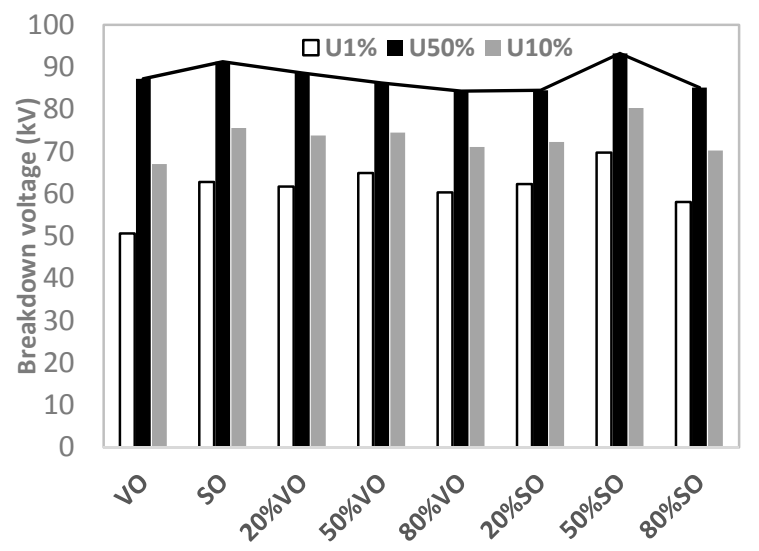

Figure 20. Probability of AC breakdown voltage of oil mixtures. 
Figures 20 and 21 give the voltages U1\%, U10\%, and U50\% determined using compliance with the Normal law. We observe that mineral oil has the least interesting dielectric strength compared to ester oils and mixtures; it has the smallest breakdown voltages with risks of $1 \%, 10 \%$, and $50 \%$ probabilities. The mixtures giving the best BDV in DC are mixtures with $80 \%$ natural ester and $50 \%$ synthetic ester while in AC the best mixture is that with $50 \%$ synthetic ester oil.

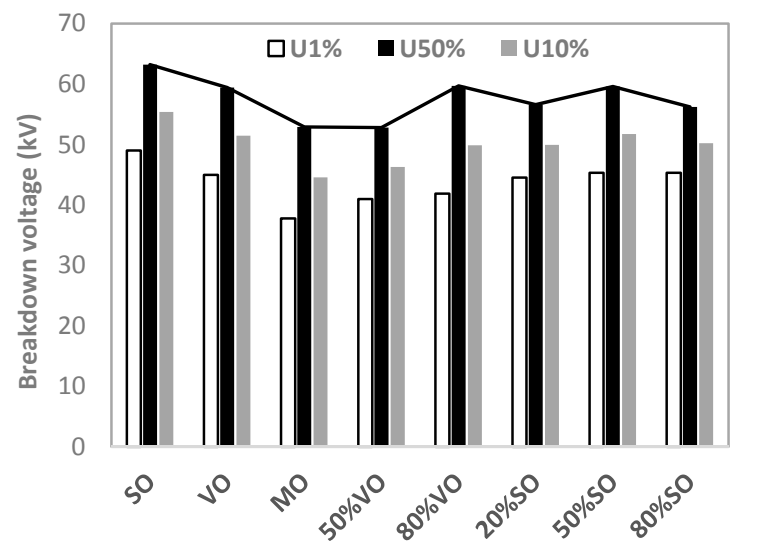

Figure 21. Probability of DC breakdown voltage of oil mixtures.

\section{Conclusions}

This work showed that:

Whatever the type of voltage (DC or AC), ester oils always have a significantly higher breakdown voltage than mineral oil. Thus vegetable oil can be used as a satisfactory alternative to mineral oil in power transformers.

The mixtures may be an option for improving the performance of mineral oil, from the point of view of dielectric strength. The addition of only $20 \%$ of natural or synthetic ester oil is sufficient to considerably increase the breakdown voltage of mineral oil. The dielectric strength of such a mixture is much higher than that of mineral oil alone and can reach that of ester oils.

The re-filling of transformers can be considered with mixtures composed of $20 \%$ of mineral oil and $80 \%$ of ester oil. In the case of vegetable oil, the breakdown voltage of the mixture remains equal to that of natural ester alone. In contrast, when the used replacement oil is synthetic ester, the dielectric strength of the mixture is decreased in comparison with that of synthetic oil.

Under AC, the mixtures with natural ester always follow the behavior of vegetable oil alone, unlike mixtures with synthetic ester, which have a breakdown voltage which varies considerably with added concentration up to exceeding that of synthetic oil alone.

Under DC, whatever the nature of ester (natural or synthetic), the dielectric strength of mixtures varies as a function of the concentration added to mineral oil and is between that of mineral oil alone and ester oils alone.

The breakdown voltage generally follows a normal distribution whatever the oil or mixture.

With the exception of the $20 \%$ mixture of natural ester in DC, all the tested mixtures were in accordance with the normal distribution, which made it possible to define the breakdown voltages for the risk levels of $1 \%, 10 \%$, and $50 \%$ of probability.

Acknowledgments: The authors would like to thank the International Scientific Partnership Program (ISPP) at King Saud University for funding this research work through ISPP\#0047. The authors extend their appreciation to Twasol Research Excellence Program, “TRE Program”, King Saud University, Saudi Arabia for its support.

Author Contributions: All the authors contributed to the realization of experimental arrangements, preparation of oil mixtures and all experimental measurements as well as the writing of the paper.

Conflicts of Interest: The authors declare no conflict of interest. 


\section{References and Note}

1. Perrier, C.; Beroual, A.; Bessede, J.-L. Improvement of power transformer by using mixtures of mineral oil with synthetic esters. IEEE Trans. Dielectr. Electr. Insul. 2006, 13, 556-564. [CrossRef]

2. Perrier, C.; Beroual, A.; Bessede, J.-L. Improvement of mineral oil properties by mixing it with synthetic esters. In Proceedings of the 15th IEEE International Conference on Dielectric Liquids (ICDL), Coimbra, Portugal, 26 June-1 July 2005.

3. Norme CEI 60814 (deuxième édition), Isolants liquides-Cartons et papiers imprégnés d'huile Détermination de la teneur en eau par titrage coulométrique de Karl Fischer automatique, August 1997.

4. Mettler Toledo Titrators DL32/DL39, Fundamentals of the Coulometric Karl Fischer Titration with Selected Application, Application Brochure. Available online: http:/ / www.mt.com/fr/fr/home.html (accessed on 31 March 2017).

5. Insulating Liquids_Determination of the Breakdown Voltage at Power Frequency -Test Method; IEC 60156 Ed. 2; International Electrotechnical Commission (IEC): Geneva, Switzerland, 1995.

6. IEEE Guide for Acceptance and Maintenance of Natural Ester Fluids in Transformers; IEEE Std C57.147; IEEE Standard Association: Washington, DC, USA, 2008.

7. Shapiro, S.S.; Wilk, M.B. An analysis of variance test for normality (complete samples). Biometrika 1965, 52, 591-611. [CrossRef]

8. Anderson, T.W.; Darling, D.A. Asymptotic theory of certain "goodness-of-fit" criteria based on stochastic processes. Ann. Math. Stat. 1952, 23, 193-212. [CrossRef]

9. Pearson, K. On lines and planes of closest fit to systems of points in space. Philos. Mag. 1901, 2, 559-572. [CrossRef]

10. The R Project for Statistical Computing. Available online: https:/ / www.r-project.org/ (accessed on 31 March 2017).

11. Dang, V.H.; Beroual, A.; Perrier, C. Comparative Study of Statistical Breakdown in Mineral, Synthetic and Natural Oil under AC Voltage. IEEE Trans. Dielectr. Electr. Insul. 2006, 13, 556-564.

(C) 2017 by the authors. Licensee MDPI, Basel, Switzerland. This article is an open access article distributed under the terms and conditions of the Creative Commons Attribution (CC BY) license (http:/ / creativecommons.org/licenses/by/4.0/). 